Original Research Paper

\title{
The Effects of Moisture Content and Loading Orientation on Some Physical and Mechanical Properties of Tiger Nut
}

\author{
1,2 Long Wang, ${ }^{1,2}$ Can Hu, ${ }^{1,2}$ Wensong Guo, ${ }^{1,2}$ Xiaowei He,,${ }^{1,2, *}$ Xufeng Wang, ${ }^{3}$ Jianming Jian and ${ }^{3}$ Shulin Hou \\ ${ }^{1}$ College of Mechanical and Electronic Engineering, Tarim University, Aral Xinjiang, 843300, China \\ ${ }^{2}$ Modern Agricultural Engineering Key Laboratory at Universities of Education, \\ Department of Xinjiang Uygur Autonomous Region, Aral Xinjiang, 843300, China \\ ${ }^{3}$ College of Engineering, China Agricultural University, Beijing, 100083, China
}

\author{
Article history \\ Received: 04-01-2021 \\ Revised: 08-03-2021 \\ Accepted: 18-03-2021 \\ Corresponding Author: \\ Xufeng Wang \\ College of Mechanical and \\ Electronic Engineering, Tarim \\ University, Aral Xinjiang, \\ 843300, China \\ Email:wxfwyq@126.com
}

\begin{abstract}
The physical and mechanical properties of the newly "Zhongyousha No.1" and the traditional "Yousha" Chinese tiger nut varieties are studied. Several physical and mechanical properties of the two tiger nut varieties were determined as a function of moisture content (at five levels of 40.0, 32.0, 24.0, 16.0 and 8.0\% wet basis). The physical and mechanical properties including length, width, thickness, geometric mean diameter, surface area, sphericity, compression rupture force, firmness, shear rupture force and shear strength. All tiger nut mechanical properties were significantly affected by moisture content $(\mathrm{P}<0.01)$. The results shows that the physical properties decreased linearly by decreasing moisture content. The compression rupture force increased linearly from the average of 175.56-208.77 $\mathrm{N}$ as moisture content increased from 8 to $40 \%$. While for the shear rupture force and shear strength decreased linearly from the average of 109.73-91.72 $\mathrm{N}$ and 1.03-0.63 MPa, respectively. There is a quadratic relationship between firmness and moisture content from the average of $51.80-65.20 \mathrm{~N} / \mathrm{m}$. The compression rupture force in the vertical loading orientation is significantly greater than that of the horizontal, while the shear rupture force is higher in the vertical than horizontal. "Yousha" tiger nut possessed higher mechanical strength than "Zhongyousha No.1". The results can be used as design parameters for suitable harvesting machinery and food processing equipment.
\end{abstract}

Keywords: Tiger Nut, Physical Properties, Mechanical Properties, Moisture Content, Variety

\section{Introduction}

Tiger nut, which is native to Africa and Mediterranean countries, is widely distributed in the Nile Valley of Egypt (Pascual et al., 2000). It can be eaten raw and is considered to have a sweet and delicious taste (Alvares et al., 2017), with freshly harvested tiger nut characteristically having a snow white flesh and a delicate fragrance. Its rich nutrition has resulted in its development into beverages, milk powder, as well as food targeted at infants, young children and the elderly (Rosello-Soto et al., 2018). Tiger nut is also frequently used as an additive for ice cream and pastries (Cantalejo, 1997). In Africa, Spain and Mexico, tiger nut is also often used to make a cool, milky sweet drink, known as "horchata de chufa" in Spain and Mexico (Abdel-Nabey, 2001; Sanchez-Zapata et al., 2012). Tiger nut has recently been adopted as an oil-bearing economic crop, with its high tuber yield that is rich in oil (Ibitoye et al., 2018) awarding it the role of the "king of oil" in plants. In particular, it is a high-quality edible oil that is rich in monounsaturated fatty acids, minerals (particularly cholesterol-free) and protein (Ezeh et al., 2014; Oderinde and Tairu, 1988). Furthermore, tiger nut oil has been associated with the prevention of hyperlipidemia and cardiovascular diseases (Codina-Torrella et al., 2015).

There are many studies on the chemical and nutritional components of tiger nuts (Abdel-Nabey, 2001; Ibitoye et al., 2018; Rehab and El Anany, 2012). Research on the physical and mechanical properties of tiger nut is limited. Oyerinde and Olalusi (2013) measured the physical properties of yellow and brown tiger nut varieties under varying moisture content, demonstrating the larger size of the yellow tiger nut 
compared to the brown varieties. Ince et al. (2017) investigated the physical and compression properties of two Turkish varieties of tiger nut under varying moisture content and determined that the variety and loading direction have relatively little effect on firmness.

Despite the physical and mechanical properties of agricultural materials playing a crucial role in the design of mechanical harvesting, sorting and processing equipment (Razavi and Edalatian, 2012; Kusumah et al., 2020), research on such properties for tiger nut is limited. Moisture content, loading direction and variety et al are the main factors, which affecting the physical and mechanical properties of agricultural materials ( $\mathrm{Su}$ et al., 2019; Durguti et al., 2020). The physical and mechanical properties of fruits and vegetables are very necessary for the reasonable design of different processing equipment (Kusumah et al., 2020; Lae et al., 2019). China is currently lacking mature harvesting machines for tiger nut. Technical limitations commonly result in mechanical damage, including the breaking and stress cracking of tiger nut during harvest, which seriously affects its quality and economic value (Mlaviwa and Missanjo, 2019). This is attributed to the distinct physical properties of Chinese and foreign tiger nut varieties, with a specific lack of research on the former.

In this study, we measured the shear strength in different loading orientation of two Chinese tiger nut varieties, namely, an old variety denoted as "Yousha" and the new cultivar "Zhongyousha No.1", which has not been reported elsewhere. Furthermore, there is no published work focusing on the effect of moisture content on different properties of Chinese tiger nuts. Hence, this study was conducted to investigate the mechanical behavior and some physical properties of two different varieties of Chinese tiger nuts, the physical and mechanical properties including length, width, thickness, geometric mean diameter, surface area, sphericity, compression rupture force, firmness, shear rupture force and shear strength. The research results can be used to design, optimize and evaluate harvesting and processing machinery for tiger nuts, such as design of cleaning units and separating equipments and calculating the allowable load imposed on the oil extractors.

\section{Materials and Methods}

The test materials "Yousha" (Y) and "Zhongyousha No.1" (Z1) were grown in Nangong city, Hebei Province, China during the 2019 growing season in a randomized complete bock design at the China Agriculture University. The tiger nuts were harvest in October of the same year via a harvesting machine. Following harvest, the tiger nuts were washed and dried and tubers with uniform size, no damage and wormhole were selected as the test samples. Five moisture content treatments were applied to the two varieties, namely 40 , $32,24,16$ and $8 \%$ (w.b.), as well as the uniaxial compression and shear in two loading orientations.
The initial moisture content was determined by oven drying each variety at $105 \pm 2^{\circ} \mathrm{C}$ for $24 \mathrm{~h}$ (Razavi et al., 2007). In order to obtain different moisture content conditions, the samples were dried in a drying box at $80^{\circ} \mathrm{C}$ (GZX-9140MBE Electric thermostatic drying oven, Shanghai Boxun Industry Co., Ltd. Shanghai, China) and taken from the drying box and measured the mass every 30 min until the required moisture content was reached. Before each drying, take about $300 \mathrm{~g}$ tiger nut for drying experiment, the moisture content is followed by the application of the following formula (Balasubramanian, 2001):

$m_{f}=\frac{m_{i}\left(100-M_{i}\right)}{100-M_{d}}$

where, $m_{f}$ and $m_{i}$ are the dried and initial mass of the samples $(\mathrm{g})$, respectively and $M_{i}$ and $M_{d}$ are the initial and desired moisture content (\% w.b.), respectively.

The three key tiger nut dimension parameters of length $(L, \mathrm{~mm})$, width $(W, \mathrm{~mm})$ and thickness $(T, \mathrm{~mm})$ were measured using a Shenzhen BiaoKang SL01-22 digital vernier caliper with an accuracy of $0.01 \mathrm{~mm}$ (Fig. 1). The geometric average diameter, sphericity and surface area were calculated via the following formula (Altuntaş et al., 2005; Arslan and Vursavus, 2008; Mohsenin, 1970):

$$
\begin{aligned}
& D_{g}=(L W T)^{1 / 3} \\
& \Phi=\frac{D_{g}}{L} \\
& S=\pi D_{g}^{2}
\end{aligned}
$$

where, $D_{g}$ is geometric average diameter $(\mathrm{mm}), \Phi$ is the sphericity $(\%)$ and $S$ is the surface area $\left(\mathrm{mm}^{2}\right)$.

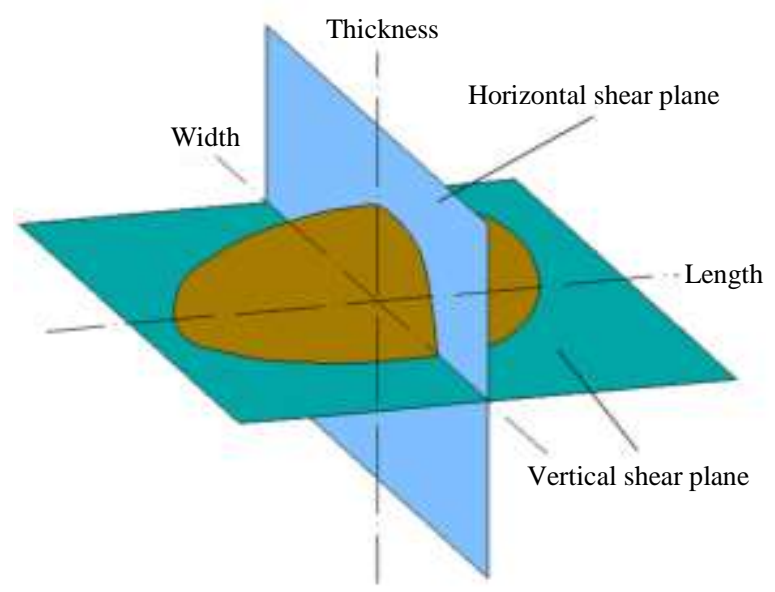

Fig. 1: Tiger nut dimension parameters and stress plane 
Uniaxial compression and shear tests were performed using a TMS Touch (Food Technology Corporation U.S.A), with a mechanical sensor range of $1000 \mathrm{~N}$ and resolution of $0.1 \mathrm{~N}$. Uniaxial compression and shear tests were carried out in both the vertical and horizontal directions. The test sample was placed between the two plates at a compression and shear rate of $5 \mathrm{~mm} / \mathrm{min}$ with an initial force recorded of $0.3 \mathrm{~N}$. Each test was repeated 20 times at room temperature.

The uniaxial compression tests were implemented in order to determine the tiger nut firmness under compression. The diameter of the upper compression plate was $75 \mathrm{~mm}$ (Fig. 2). The firmness is expressed as the ratio of the compression force to deformation value at fracture (Khazaei et al., 2002):

$Q=\frac{F}{D}$

where, $Q$ is the firmness $(\mathrm{N} / \mathrm{mm}), F$ is the compression force at the rupture point $(\mathrm{N})$ and $D$ is the deformation at the rupture point $(\mathrm{mm})$.
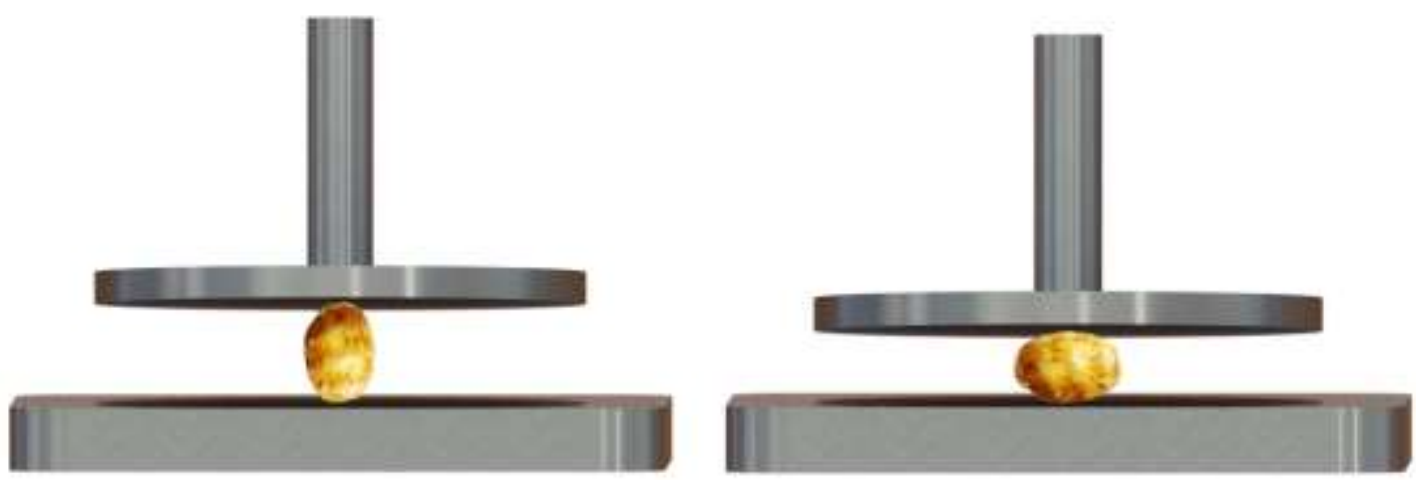

Fig. 2: Uniaxial compression test of tiger nut under different loading axis (a) vertical axis of tiger nut in line with loading orientation, (b) horizontal axis of tiger nut in line with loading orientation
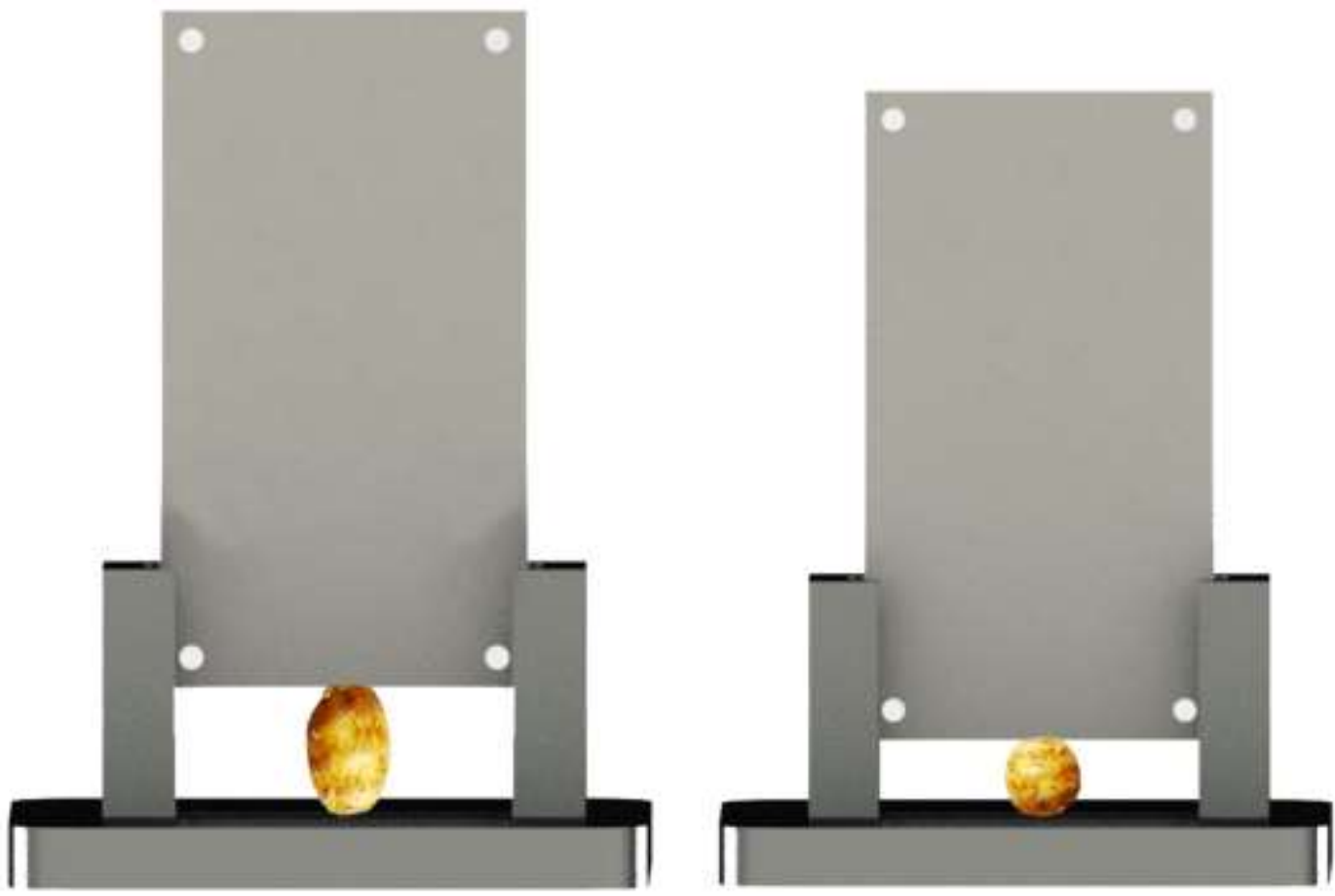

Fig. 3: Shear tests of tiger nut under different loading axis (a) vertical axis of tiger nut in line with loading orientation, (b) horizontal axis of tiger nut in line with loading orientation 
Shear tests were employed in order to determine the shear strength of the tiger nut under shear stress. The thickness of the upper shear plate used in the experiments was $1 \mathrm{~mm}$ (Fig. 3). The shear strength is expressed as the ratio of force to area at the splitting point (Tavakoli et al., 2009):

$\tau_{s}=\frac{F}{A}$

where, $\tau_{s}$ is the shear strength (MPa), $F$ is the shear force at the fracture point $(\mathrm{N})$ and $A$ is the stress area $\left(\mathrm{mm}^{2}\right)$. The stress areas in the vertical and horizontal directions were determined as $A=\frac{\pi(L+W)^{2}}{16}$ and $A=\frac{\pi(W+T)^{2}}{16}$, respectively (Fig. 1).

We analyzed the effects of five moisture content levels and two varieties on the physical properties of tiger nut. In addition, the impacts of the five moisture contents, two varieties and two stress orientations on the mechanical properties (e.g., fracture force, fracture point displacement, firmness, shear strength and energy absorption) were also analyzed. Duncan's multiple range test was employed to compare the mean values of the parameters. Furthermore, we performed polynomial fitting with water content as the independent variable and fracture force as the dependent variable. SPSS Statistics 20 (IBM) was used for the data analysis and Origin 8.6 (OriginLab) was applied to view and plot the results.

\section{Results}

The mean value and standard deviation of the physical property parameters from the two varieties of Chinese tiger nut are summarized in Table 1. Also, the linear regression analysis (with generic form of $a+$ $\left.b^{*}\left(M_{c}\right)\right)$ are presented in Table 2 . It is showed that the change of physical properties can be related to be the moisture content. In this study, the effect of moisture content on the physical properties of two tiger nut were found to be significant for length, width, thickness, geometric mean diameter, surface area and sphericity $(\mathrm{P}<0.01)$. With the exception of sphericity $(\mathrm{P}=0.628)$, the effect of variety on all other physical parameters was significant $(\mathrm{P}<0.01)$.

The axial dimension, including Length (L), Width (W) and Thickness (T) of Chinese tiger nut measured at five moisture content from 8 to $40 \%$ (w.b.) are shown in Table 1. The slope of regression equation for the axial dimensions of the tiger nuts is positive (Table 2). More specifically, the length, width and thickness of the $\mathrm{Y}$ and Z1 varieties were reduced by (6.3 and 8.8\%), (11.7 and $13.7 \%)$ and $(24.2$ and $23.3 \%)$ respectively, with the reduction in the thickness being the most prominent. The statistical analysis also showed that the moisture content had significant effect $(\mathrm{P}<0.01)$ on all axial dimensions (Table 3). The reason for this increase may be due to the penetration of water in the intercellular space, resulting in the protrusion of the sample. In addition, the geometric mean diameter of the tiger nut decreased with moisture content by 14.6 and $15.5 \%$, respectively. The slopes of regression lines for axial dimensions versus moisture content of variety $\mathrm{Y}$ were greater than variety $\mathrm{Z} 1$. To give more detail, the length, width and thickness of $Y$ were 1.37, 1.21 and 1.05 times that of $Z 1$. This may be because the variety $Y$ is larger flesh. In this respect, the water absorbed by the variety $\mathrm{Y}$ interstices was more than that of variety Z1intersticesto achieve the same moisture content.

The changes of surface area with the tiger nut moisture content are shown in Table 1. Table 2 shows the change in the slope of the trend lines of the surface area with moisture content. The coefficient of the equation shows that the change rate of surface area with moisture content is very large. Duncan's (Ince et al., 2017) multiple range test results demonstrate that the $Y$ variety lengths belong to the same group statistically for all five moisture content levels, with no significant differences between values.

Table 1: Tiger nut physical properties (mean \pm standard deviation) determined from experiments

\begin{tabular}{|c|c|c|c|c|c|c|}
\hline \multirow[b]{2}{*}{ Properties } & \multirow[b]{2}{*}{ Variety } & \multicolumn{5}{|c|}{ Moisture content (\% w.b.) } \\
\hline & & 40 & 32 & 24 & 16 & 8 \\
\hline \multirow[t]{2}{*}{ Length (mm) } & $\mathrm{Y}$ & $15.33 \pm 1.10^{\mathrm{a}}$ & $14.92 \pm 0.82^{\mathrm{a}}$ & $14.70 \pm 0.88^{\mathrm{a}}$ & $14.44 \pm 0.88^{\mathrm{a}}$ & $14.36 \pm 0.99^{\mathrm{a}}$ \\
\hline & $\mathrm{Z1}$ & $14.48 \pm 0.89^{\mathrm{a}}$ & $14.08 \pm 1.19^{\mathrm{ab}}$ & $14.01 \pm 0.75^{\mathrm{ab}}$ & $13.35 \pm 0.77^{\mathrm{ab}}$ & $13.20 \pm 1.04^{\mathrm{b}}$ \\
\hline \multirow[t]{2}{*}{ Width (mm) } & $\mathrm{Y}$ & $14.45 \pm 0.75^{\mathrm{a}}$ & $13.82 \pm 0.85^{\mathrm{ab}}$ & $13.32 \pm 1.00^{\mathrm{b}}$ & $13.17 \pm 0.87^{\mathrm{b}}$ & $12.76 \pm 0.97^{\mathrm{b}}$ \\
\hline & $\mathrm{Z1}$ & $13.87 \pm 1.07^{\mathrm{a}}$ & $13.26 \pm 0.84^{\mathrm{a}}$ & $12.89 \pm 0.61^{\mathrm{ab}}$ & $12.09 \pm 0.95^{\mathrm{b}}$ & $11.97 \pm 0.91^{\mathrm{b}}$ \\
\hline \multirow[t]{2}{*}{ Thickness (mm) } & $\mathrm{Y}$ & $11.89 \pm 0.58^{\mathrm{a}}$ & $10.84 \pm 0.90^{\mathrm{b}}$ & $10.69 \pm 0.67^{b}$ & $9.98 \pm 0.95^{\mathrm{bc}}$ & $9.01 \pm 0.98^{\mathrm{c}}$ \\
\hline & $\mathrm{Z1}$ & $11.27 \pm 0.98^{\mathrm{a}}$ & $10.82 \pm 0.88^{\mathrm{a}}$ & $9.41 \pm 0.90^{\mathrm{b}}$ & $9.13 \pm 0.99^{b}$ & $8.64 \pm 0.80^{\mathrm{b}}$ \\
\hline \multirow[t]{2}{*}{ Geometric mean diameter $(\mathrm{mm})$} & $\mathrm{Y}$ & $13.80 \pm 0.52^{\mathrm{a}}$ & $13.05 \pm 0.37^{\mathrm{b}}$ & $12.78 \pm 0.55^{\mathrm{bc}}$ & $12.36 \pm 0.54^{\mathrm{cd}}$ & $11.79 \pm 0.61^{\mathrm{d}}$ \\
\hline & $\mathrm{Z1}$ & $13.12 \pm 0.82^{\mathrm{a}}$ & $12.63 \pm 0.69^{\mathrm{ab}}$ & $11.92 \pm 0.52^{\mathrm{bc}}$ & $11.36 \pm 0.73^{c}$ & $11.09 \pm 0.74^{\mathrm{c}}$ \\
\hline \multirow[t]{2}{*}{ Surface area $\left(\mathrm{mm}^{2}\right)$} & $\mathrm{Y}$ & $599.06 \pm 45.29^{a}$ & $535.64 \pm 30.07^{\mathrm{b}}$ & $513.74 \pm 44.55^{\mathrm{bc}}$ & $480.70 \pm 41.92^{\mathrm{cd}}$ & $438.08 \pm 44.85^{\mathrm{d}}$ \\
\hline & $\mathrm{Z} 1$ & $542.28 \pm 69.09^{\mathrm{a}}$ & $502.15 \pm 54.40^{\mathrm{ab}}$ & $446.93 \pm 38.71^{\mathrm{bc}}$ & $407.05 \pm 51.02^{\mathrm{c}}$ & $387.61 \pm 52.74^{\mathrm{c}}$ \\
\hline \multirow{2}{*}{ Sphericity (\%) } & $\mathrm{Y}$ & $90.25 \pm 4.19^{a}$ & $87.66 \pm 3.88^{\mathrm{ab}}$ & $87.03 \pm 3.32^{\mathrm{ab}}$ & $85.74 \pm 3.83^{\mathrm{ab}}$ & $82.36 \pm 5.53^{\mathrm{b}}$ \\
\hline & $\mathrm{Z} 1$ & $90.64 \pm 2.64^{\mathrm{a}}$ & $89.88 \pm 3.64^{\mathrm{a}}$ & $85.15 \pm 3.51^{\mathrm{b}}$ & $85.18 \pm 4.54^{\mathrm{b}}$ & $84.09 \pm 3.40^{\mathrm{b}}$ \\
\hline
\end{tabular}


Table 2: Parameters of linear regression analysis $\left(a+b^{*}\left(M_{c}\right)\right)$ with their respective coefficient of determination $\left(\mathrm{R}^{2}\right)$ and RMSE for physical properties of two types of Chinese tiger nut versus dimensionless moisture content

\begin{tabular}{|c|c|c|c|c|c|c|c|c|}
\hline \multirow[b]{2}{*}{ Property } & \multicolumn{4}{|l|}{$\mathrm{Y}$} & \multicolumn{4}{|l|}{$\mathrm{Z} 1$} \\
\hline & $\mathrm{a}$ & $\mathrm{b}$ & $\mathrm{R}^{2}$ & RMSE & $\mathrm{a}$ & $\mathrm{b}$ & $\mathrm{R}^{2}$ & RMSE \\
\hline Length (mm) & 14.030 & 0.030 & 0.9486 & 0.1026 & 12.84 & 0.041 & 0.9452 & 0.1443 \\
\hline Width (mm) & 12.290 & 0.051 & 0.9600 & 0.1506 & 11.33 & 0.062 & 0.9655 & 0.1710 \\
\hline Thickness (mm) & 8.495 & 0.083 & 0.9590 & 0.2501 & 7.77 & 0.087 & 0.9399 & 0.3205 \\
\hline Geometric mean diameter $(\mathrm{mm})$ & 11.350 & 0.059 & 0.9792 & 0.1252 & 10.42 & 0.067 & 0.9828 & 0.1285 \\
\hline Surface area $\left(\mathrm{mm}^{2}\right)$ & 400.400 & 4.711 & 0.9747 & 11.1097 & 335.90 & 5.056 & 0.9782 & 11.0340 \\
\hline Sphericity $(\%)$ & 81.300 & 0.221 & 0.9395 & 0.8203 & 81.65 & 0.223 & 0.8622 & 1.2990 \\
\hline
\end{tabular}

Table 3: The parameter test results of physical properties

\begin{tabular}{lllllll}
\hline Properties & Length & Width & Thickness & Geometric mean diameter & Surface area & Sphericity \\
\hline Moisture content(MC) & $0.002^{* *}$ & $0.000^{* *}$ & $0.000^{* *}$ & $0.000^{* *}$ & $0.000^{* *}$ & $0.000^{* * *}$ \\
Variety(V) & $0.000^{* *}$ & $0.000^{* *}$ & $0.001^{* *}$ & $0.000^{* *}$ & $0.000^{* *}$ & $0.628^{\mathrm{ns}}$ \\
\hline
\end{tabular}

*,**: Significant at the levels of 5 and $1 \%$, respectively. ns: Not significant

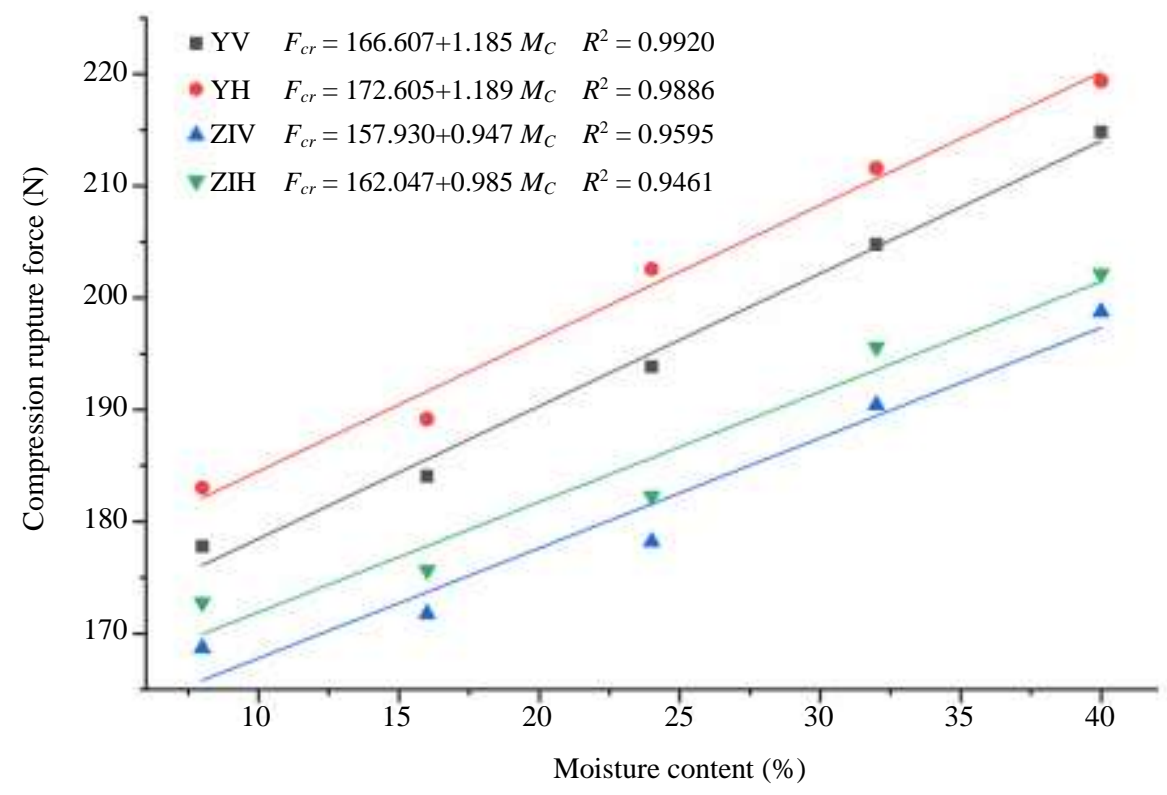

Fig. 4: Effect of moisture content on the compression rupture force $\left(F_{\mathrm{cr}}, \mathrm{N}\right)$ of Chinese Tiger nut

Sphericity, which represents the shape characteristics of the material, also decreased with moisture content by 8.7 and $7.2 \%$, respectively. The regression equation of the relationship between sphericity and moisture content is represented in Table 2 . The results show that sphericity decreases linearly with decrease of moisture content. Table 3 shows that the lack of differences in the sphericity parameters between the $\mathrm{Y}$ and $\mathrm{Z} 1$ tiger nut varieties $(\mathrm{P}=0.628)$.

Same letters within a column denote means that are not significantly different at the 0.01 significance using Duncan's multiple range test.

Figure 4 displays the compression rupture force $\left(F_{\text {cr }}\right)$ results of the two tiger nut varieties under different moisture contents. The compression rupture force of both varieties significantly exhibited a linear decrease from the average of 175.56-208.77 $\mathrm{N}(\mathrm{P}<0.01)$ as the moisture content was reduced.

For both varieties, the compression rupture force in the vertical loading orientation (mean values for both varieties $188.31 \mathrm{~N}$, respectively) is significantly bigger $(\mathrm{P}<0.01)$ than that in the horizontal loading orientation (mean values for both varieties $193.41 \mathrm{~N}$, respectively). This can be attributed to the larger stress area in the horizontal orientation compared to that of the vertical orientation eventually. Across all moisture content, the compression rupture force varied between 168.68 and $214.81 \mathrm{~N}$ in the vertical loading orientation and 172.76 and $219.36 \mathrm{~N}$ in the horizontal loading direction. According to the results of the tests, the effect of variety on the compression rupture force was significant $(\mathrm{P}<0.01)$. 
Figure 5 presents the Firmness (F) determined for the two tiger nut varieties under different moisture contents. The firmness values of the tiger nut at rupture point decreased nonlinearly as the moisture content decreased. The reason for this is the high decrease in deformation at low moisture content levels. Significant differences $(\mathrm{P}<0.05)$ in firmness were observed between the two varieties.
Firmness values in the vertical and horizontal loading orientations ranged from (59.94 and $76.34 \mathrm{~N} / \mathrm{mm}$ ) and (41.73 and $57.71 \mathrm{~N} / \mathrm{mm}$ ), respectively. The firmness values in the horizontal loading orientation were approximately 1.5 times larger than those of the vertical loading orientation and this difference was significant $(\mathrm{P}<0.01)$. The effect of moisture content on firmness was also statistically significant $(\mathrm{P}<0.01)$.

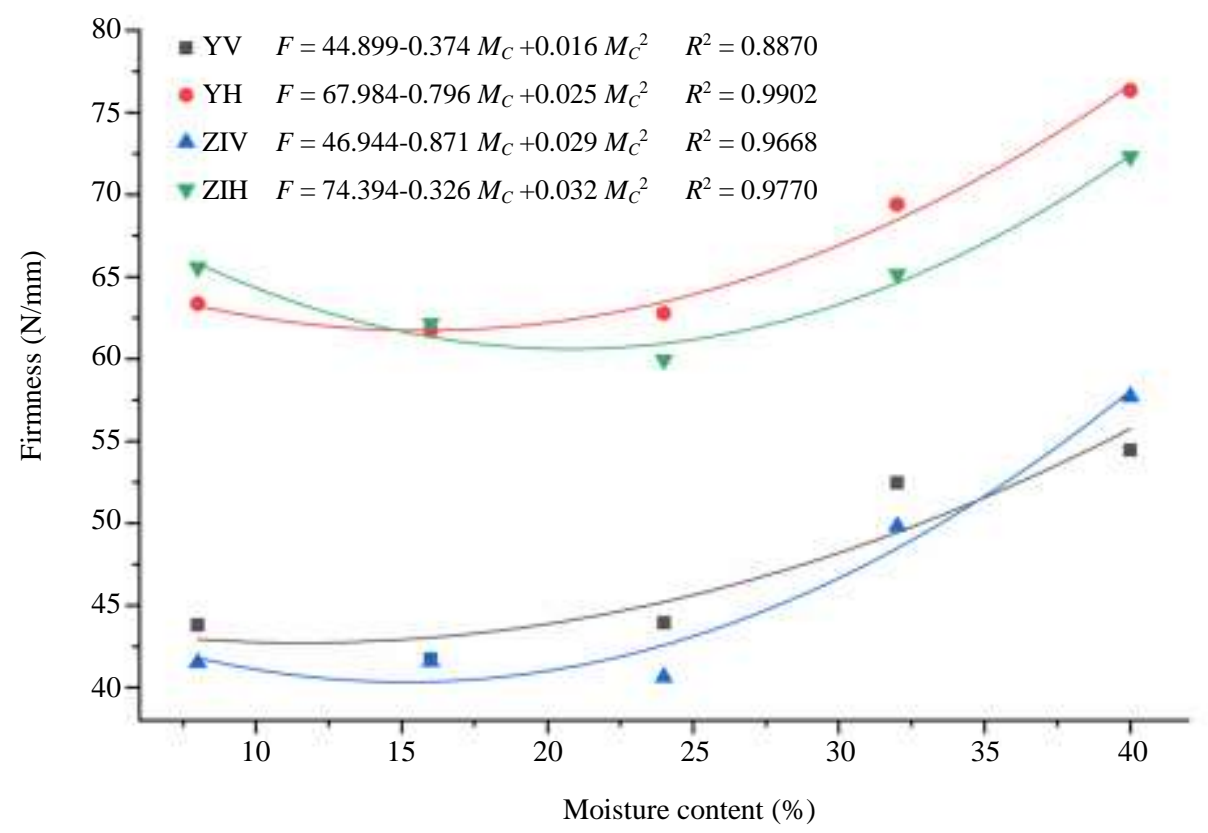

Fig. 5: Effect of moisture content on the firmness $(F, \mathrm{Nmm})$ of Chinese Tiger nut

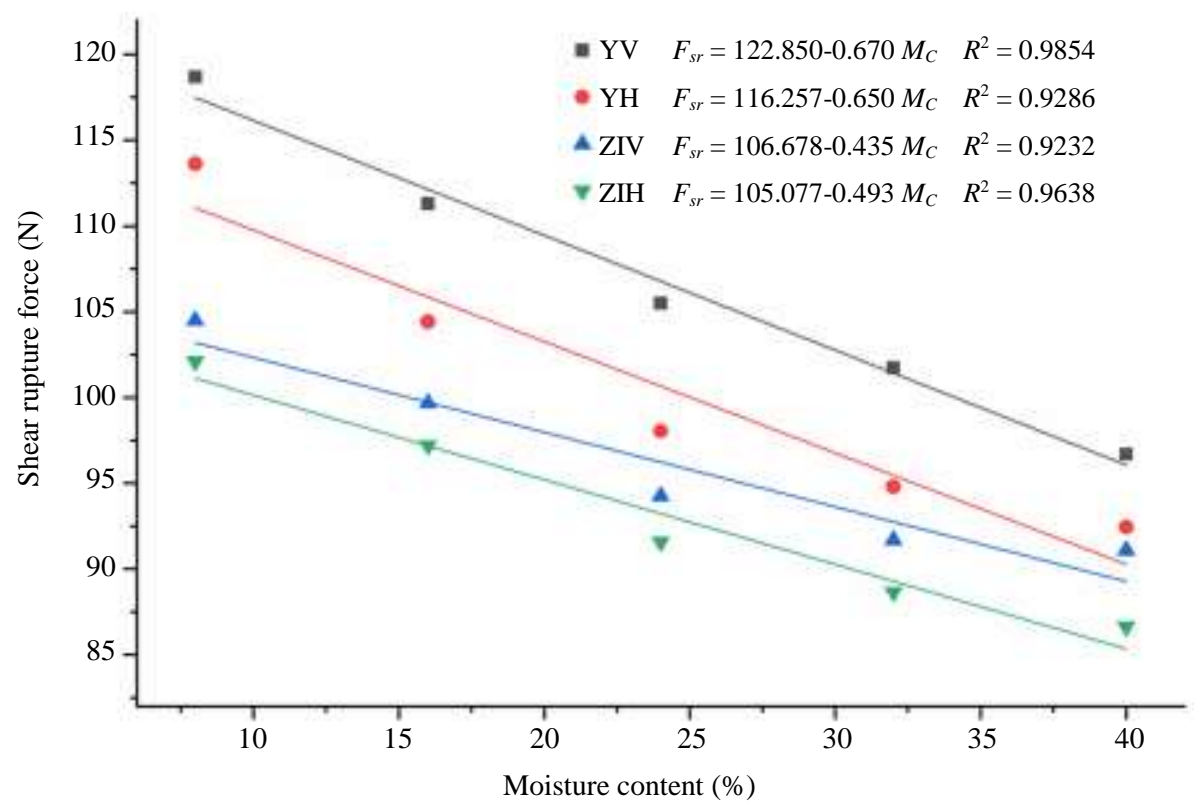

Fig. 6: Effect of moisture content on the shear rupture force $\left(F_{\mathrm{sr}}, \mathrm{N}\right)$ of Chinese Tiger nut 


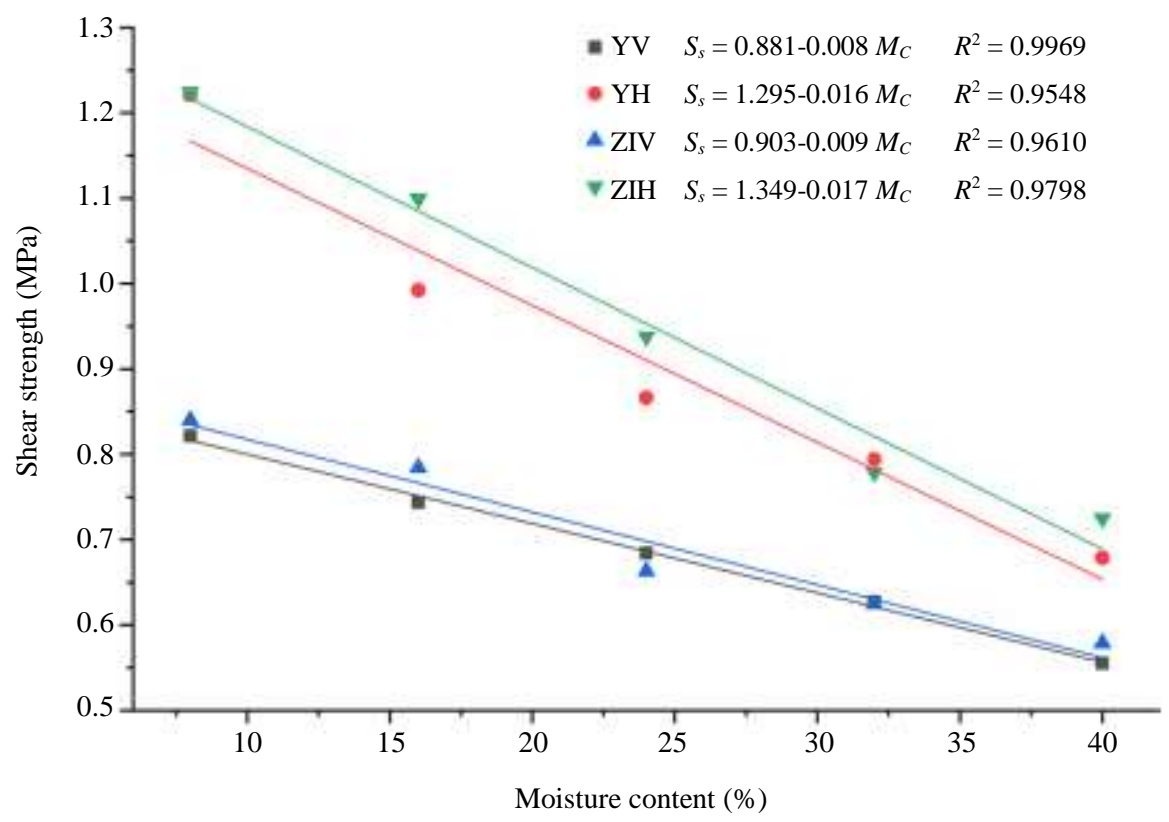

Fig. 7: Effect of moisture content on the shear strength $\left(S_{\mathrm{s}}, \mathrm{MPa}\right)$ of Chinese Tiger nut

Figure 6 presents the shear rupture force $\left(F_{\mathrm{sr}}\right)$ of the two tiger nut varieties under different moisture contents. The shear rupture force increased as the moisture content decreases for both varieties and loading orientations. This may be explained by the differences in moisture content, the lower the moisture content, the firmer and the internal structure of tiger nut. The shear rupture forces of the two varieties were significantly higher $(\mathrm{P}<0.01)$ in the vertical than horizontal loading orientation, ranging from $(91.09$ and $118.69 \mathrm{~N})$ and $(86.66$ and $113.63 \mathrm{~N})$, respectively. The test result demonstrates that the effect of moisture content, loading orientation and varieties on the shear rupture force was significant $(\mathrm{P}<0.01)$. This is because the shear crosssectional area of horizontal loading orientation is smaller than that of vertical loading direction.

Figure 7 presents the Shear strength (Ss) of the two tiger nut varieties determined for different moisture content values. The shear strength increased as the moisture content decreased, reaching a maximum of 1.22 MPa for both varieties at the moisture content of $8 \%$.

Furthermore, the shear strength in the horizontal loading orientation was significantly greater $(\mathrm{P}<0.01)$ than that in the vertical orientation, with ranges of $(0.68$ and $1.19 \mathrm{MPa}$ ) and (0.56 and $0.84 \mathrm{MPa})$, respectively. The test result reveals the variety on the shear strength to be significant $(\mathrm{P}<0.05)$.

\section{Discussion}

The result indicated that the axial dimensions are increased with the increasing of moisture content. Ince et al.
(2017; Oyerinde and Olalusi, 2013) have reported similar trends for two tiger nut varieties. Abano and Amoah (2011) reported that the dimension of black variety of tiger nut ranged from 13.71 to $16.16 \mathrm{~mm}$ in length, 12.46 to $14.51 \mathrm{~mm}$ in width, 10.40 to 11.94 $\mathrm{mm}$ in thickness and 11.80 to $13.69 \mathrm{~mm}$ in geometric mean diameter for moisture content from 17 to $32 \%$ (w.b.). These values are close to the general value of Chinese tiger nut variety Y. Our sphericity values are slightly larger than those of (Abano and Amoah, 2011; Ince et al., 2017). Compared with foreign varieties, the sphericity value of Chinese tiger nut is larger. The results of the current study demonstrate the lack of differences in the sphericity parameters between the $Y$ and $\mathrm{Z} 1$ tiger nut varieties $(\mathrm{P}>0.05)$, while significant differences were observed for other physical parameters $(\mathrm{P}<0.01)$ and the sphericity decreases linearly with decrease in moisture content. These results indicated that the different size circular holes could be used to sieving particle for different varieties of tiger nut. At the same time, the size of the screen of tiger nut should be considered in different harvest periods. In particular, the tiger nut length, width, thickness, geometric average diameter, surface area and sphericity, decreased with moisture content. The thickness exhibited the most obvious reductions (24.2 and $23.3 \%$ for $\mathrm{Y}$ and $\mathrm{Z} 1$, respectively) as the moisture content decreased from 40 to $8 \%$. The effect of moisture content on length, width, thickness, average diameter, sphericity, surface area was significant $(\mathrm{P}<0.01)$.

All tiger nut compression and shear mechanical properties were significantly affected by moisture 
content $(\mathrm{P}<0.01)$. The compressive fracture force and firmness decreased with the moisture content, while the shear rupture force and shear strength increased. Therefore, at high water content, it can resist compression, but not shear. It is suggested to harvest, package or transport when the moisture content of Chinese tiger nuts is more than $30 \%$. The compression rupture force and shear rupture force of the $\mathrm{Y}$ variety were greater than those of the $\mathrm{Z1}$ variety, reaching 219.36 and $118.69 \mathrm{~N}$. The effect of varieties and loading orientation on the compression rupture force, firmness, shear rupture force and shear strength were significant $(\mathrm{P}<0.05)$. Our results demonstrate that the moisture content, variety and loading orientation have a significant impact on the physical and mechanical properties of tiger nut. Thus, the influence of moisture content, variety and loading orientation should be comprehensively considered in the design of harvest machinery and food processing equipment. This study evaluated the physical and mechanical properties of Chinese cultivar tiger nut and provides reference data to develop suitable conditions for harvesting, storing and handling of tiger nut.

It should be noted that only some physical and mechanical properties of Chinese tiger nuts obtained in this study. In further research, the contact parameters of Chinese tiger nuts and different materials should be researched and the influence of root and stem of tiger nuts under actual working conditions should be considered.

\section{Acknowledgment}

The authors thank the College of Engineering, China Agriculture University for the laboratory support during this research. This study was supported by Joint fund of China Agricultural University and Tarim University (Project No. ZNLH201901), Key Laboratory of Colleges \& Universities under the Department of Education of Xinjiang (Project No. TDNG2020104) and China Agricultural University's support research cooperation fund (Project No. 2020SF003).

\section{Author's Contributions}

Long Wang and Can Hu: Designed and performed the experiments work.

Wensong Guo, Xiaowei He and Xufeng Wang: Participated to collect the materials related to the experiment.

Jianming Jian and Shulin Hou: Revised the manuscript.

\section{Ethics}

The authors declare their responsibility for any ethical issues that may arise after the publication of this manuscript.

\section{Conflict of Interest}

The authors declare that they have no competing interests. The corresponding author affirms that all of the authors have read and approved the manuscript.

\section{References}

Abano, E. E., \& Amoah, K. K. (2011). Effect of moisture content on the physical properties of tiger nut (Cyperus esculentus). Asian Journal of Agricultural Research, $5(1)$,

56-66. https://doi.org/10.3923/ajar.2011.56.66

Abdel-Nabey, A. A. (2001). Chemical and technological studies on chufa (tiger nut) tubers (Cyperus esculentus L.). Alexandria Journal of Agricultural Research, 46(3), 71-80.

Altuntaş, E., Özgöz, E., \&Taşer, Ö. F. (2005). Some physical properties of fenugreek (Trigonella foenum-graceum L.) seeds. Journal of Food Engineering, 71(1), 37-43. https://doi.org/10.1016/j.jfoodeng.2004.10.015

Alvares, D., Armero, C., Forte, A., Serra, J., Galipienso, L., \& Rubio, L. (2017). Incidence and control of black spot syndrome of tiger nut. Annals of Applied Biology, 171(3), 417-423. https://doi.org/10.1111/aab.12384

Arslan, S., \& Vursavus, K. K. (2008). Physicomechanical properties of almond nut and its kernel as a function of variety and moisture content. Philippine Agricultural Scientist, 91(2), 171-179.

Balasubramanian, D. (2001). Physical properties of raw cashew nut. Journal of Agricultural Engineering Research, 78(3), 291-297. https://doi.org/10.1006/jaer.2000.0603

Cantalejo, M. J. (1997). Analysis of volatile components derived from raw and roasted earth-almond (Cyperus esculentus L). Journal of Agricultural and Food Chemistry, 45(5), 1853-1860. https://doi.org/10.1021/jf960467m

Codina-Torrella, I., Guamis, B., \& Trujillo, A. J. (2015). Characterization and comparison of tiger nuts (Cyperus esculentus L.) from different geographical origin Physico-chemical characteristics and protein fractionation. Industrial Crops and Products, 65, 406-414. https://doi.org/10.1016/j.indcrop.2014.11.007

Durguti, V., Aliu, S., Laha, F., \& Feka, F. (2020). Determination of iron, copper and zinc in the wine by faas. Emerging Science Journal, 4(5), 411-417. https://doi.org/10.28991/esj-2020-01240

Ezeh, O., Gordon, M. H., \& Niranjan, K. (2014). Tiger nut oil (Cyperus esculentus L.): A review of its composition and physico-chemical properties. European Journal of Lipid Science and Technology, 116(7), 783-794. https://doi.org/10.1002/ejlt.201300446 
Ibitoye, O. B., Aliyu, N. O., \&Ajiboye, T. O. (2018). Tiger nut oil-based diet improves the lipid profile and antioxidant status of male Wistar rats. Journal of Food Biochemistry, 42(5). https://doi.org/10.1111/jfbc. 12587

Ince, A., Vursavus, K. K., Vurarak, Y., Cubukcu, P., \&Cevik, M. Y. (2017). Selected engineering properties of tiger nut as a function of moisture content and variety. Turkish Journal of Agriculture and Forestry, 41(4), 263-271. https://doi.org/10.3906/tar-1612-38

Khazaei, J., Borghei, A. M., Rasekh, M., \&Rabani, H. (2002). Physical and mechanical properties of almond and its kernel related to cracking and peeling. In S. Kosutic (Ed.), Actual Tasks on Agricultural Engineering, Proceedings (Vol. 30, pp. 353-365). https://elibrary.asabe.org/abstract.asp?aid=10847

Kusumah, S. H., Andoyo, R., \&Rialita, T. (2020). Isolation and characterization of red bean and green bean protein using the extraction method and isoelectric ph. Science Medicine Journal, 2(2), 77-85. https://doi.org/10.28991/SciMedJ-2020-0202-5

Lae, K. Z. W., Su, S. S., Win, N. N., Than, N. N., \& Ngwe, H. (2019). Isolation of lasiodiplodin and evaluation of some biological activities of the stem barks of phyllanthusalbizzioides (kurz) hook.f. Sci Medicine Journal, 1(4). https://doi.org/10.28991/SciMedJ-2019-0104-5

Mlaviwa, J., \& Missanjo, E. (2019). Recent trends and future directions on value addition of irish potato (solanum tuberosum 1.) among smallholder farmers. Emerging Science Journal, 3(1), 41. https://doi.org/10.28991/esj-2019-01167

Mohsenin, N. N. (1970). Physical properties of plant and animal materials. New York: Gordon and Breach Science Publisher.

Oderinde, R. A., \& Tairu, O. A. (1988). Evaluation of the Properties of Yellow Nutsedge (Cyperus-Esculentus) Tuber Oil. Food Chemistry, 28(3), 233-237. https://doi.org/10.1016/0308-8146(88)90055-6

Oyerinde, A. S., \& Olalusi, A. P. (2013). Effect of moisture content on selected physical and mechanical properties of two varieties of tiger nut (Cyperus spp). Journal of Food Research, 2(6), 24-32. https://doi.org/10.5539/jfr.v2n6p24

Pascual, B., Maroto, J. V., Lopez-Galarza, S., Sanbautista, A., \& Alagarda, J. (2000). Chufa (Cyperus esculentus L. var. sativus Boeck.): An unconventional crop. studies related to applications and cultivation. Economic Botany, 54(4), 439-448. https://doi.org/10.1007/BF02866543
Razavi, S. M. A., \& Edalatian, M. R. (2012). Effect of Moisture Contents and Compression Axes on Physical and Mechanical Properties of Pistachio Kernel. International Journal of Food Properties, $15(3)$, 507-517. https://doi.org/10.1080/10942912.2010.492541

Razavi, S. M. A., Emadzadeh, B., Rafe, A., \& Amini, A. M. (2007). The physical properties of pistachio nut and its kernel as a function of moisture content and variety: Part I. Geometrical properties. Journal of Food Engineering, 81(1), 209-217. https://doi.org/10.1016/j.jfoodeng.2006.11.003

Rehab, F. M. A., \& El Anany, A. M. (2012). Physicochemical studies on sunflower oil blended with cold pressed tiger nut oil during the deep frying process. Grasas Y Aceites, 63(4), 455-465. https://doi.org/10.3989/gya.057612

Rosello-Soto, E., Poojary, M. M., Barba, F. J., Lorenzo, J. M., Manes, J., \& Carlos Molto, J. (2018). Tiger nut and its by-products valorization: From extraction of oil and valuable compounds to development of new healthy products. Innovative Food Science \& Emerging Technologies, 45, 306-312. https://doi.org/10.1016/j.ifset.2017.11.016

Sanchez-Zapata, E., Fernandez-Lopez, J., \& Angel Perez-Alvarez, J. (2012). Tiger Nut (Cyperus esculentus) Commercialization: Health Aspects, Composition, Properties and Food Applications. Comprehensive Reviews in Food Science and Food Safety, 11(4), 366-377. https://doi.org/10.1111/j.1541-4337.2012.00190.x

Su, Y., Cui, T., Zhang, D., Xia, G., Gao, X., He, X., \& $\mathrm{Xu}, \mathrm{Y}$. (2019). MLR and experimental testing for characterization and classification of damage resistance of maize hybrids based on mechanical properties. Journal of Food Process Engineering, 42(7). https://doi.org/10.1111/jfpe.13262

Tavakoli, H., Mohtasebi, S. S., \& Jafari, A. (2009). Effects of moisture content, internode position and loading rate on the bending characteristics of barley straw. Research in Agricultural Engineering, 55(2), 45-51. https://doi.org/10.17221/26/2008-RAE 